\title{
SERVIÇO SOCIAL E HUMANIZAÇÃO: EXPERIÊNCIA DA RESIDÊNCIA EM SAÚDE - UNIVERSIDADE FEDERAL DO TRIÂNGULO MINEIRO - UFTM
}

\author{
Andreia Cristina Rodrigues ${ }^{1}$ \\ Ivone Aparecida Vieira da Silva ${ }^{2}$ \\ Karen Costa Aguiar ${ }^{3}$ \\ Marta Regina Farinelli ${ }^{4}$ \\ Regina Maura Rezende ${ }^{5}$ \\ Rosane Aparecida de Sousa Martins ${ }^{6}$ \\ Suely Aparecida Alberto Melo ${ }^{7}$ \\ Verena Conti ${ }^{8}$ \\ Zilda Cristina dos Santos ${ }^{9}$
}

\section{RESUMO}

A humanização tem sido associada a diferentes e complexas categorias relacionadas à produção e gestão de cuidados em saúde, tais como: integralidade, satisfação do usuário, necessidades de saúde, qualidade da assistência, gestão participativa, protagonismo dos sujeitos, além de uma assistência capaz de prover acolhimento, resolutividade, e ainda, visar à melhoria da qualidade de vida dos sujeitos. Discutir o trabalho do assistente social na área da saúde com enfoque na Política de Humanização nos remete a algumas características que desvendam a particularidade desse complexo processo de trabalho, no qual o Serviço Social é historicamente e culturalmente identificado como uma das profissões da saúde que tem se dedicado às questões relativas à humanização do atendimento. Este artigo propõe a reflexão acerca da

\footnotetext{
${ }^{1}$ Assistente Social Residente Multiprofissional Área de Concentração Saúde da Criança e Adolescente, UFTM.

${ }^{2}$ Assistente Social Coordenadora do Setor de Serviço Social do Hospital de Clínicas, UFTM e Preceptora do Programa de Residência Integrada Multiprofissional em Saúde - UFTM.

3 Assistente Social do Hospital de Clínicas da UFTM e Preceptora do Programa de Residência Multiprofissional em Saúde - UFTM.

${ }^{4}$ Assistente Social, Doutora em Serviço Social, Docente do Curso de Serviço Social - UFTM e Tutora do Programa de Residência Integrada Multiprofissional da Universidade Federal do Triangulo Mineiro UFTM.

5 Assistente Social, Doutora em Serviço Social, Docente do Curso de Serviço Social - UFTM e Tutora do Programa de Residência Integrada Multiprofissional da Universidade Federal do Triangulo Mineiro UFTM.

${ }^{6}$ Assistente Social, Doutora em Serviço Social, Docente do Curso de Serviço Social - UFTM e Tutora do Programa de Residência Integrada Multiprofissional da Universidade Federal do Triangulo Mineiro UFTM.

${ }^{7}$ Assistente Social - Residente Multiprofissional área de concentração Saúde do Idoso - UFTM.

8 Assistente Social do Hospital de Clínica - UFTM e Preceptora do Programa de Residência Integrada Multiprofissional em Saúde-UFTM.

9 Assistente Social - Residente Multiprofissional área de concentração Saúde do Adulto - UFTM. Revista Serviço Social \& Saúde. UNICAMP Campinas, v. X, n. 12, Dez. 2011
} 
experiência do Serviço Social na Residência Multiprofissional em Saúde tendo como premissa o compromisso com o reconhecimento da saúde como resultante das condições de vida, derivadas das condições econômicas, políticas, sociais e culturais da população. A partir desta experiência evidenciou-se a relevância do Serviço Social para equipe multiprofissional no sentido de contribuir para a articulação, identificação e produção de informações acerca da realidade social marcada pelas contradições que se traduzem na desigualdade que desumaniza, subtrai e ainda, exclui. $\mathrm{O}$ assistente social tem o compromisso ético-político de trazer para o espaço institucional a informação, o conhecimento e o saber desconhecido pela população usuária, corroborando assim para a edificação de seu projeto ético político profissional bem como para o fortalecimento das ações voltadas para a humanização em saúde.

PALAVRAS-CHAVES: Serviço Social, Residência Multiprofissional, Humanização, Políticas Públicas.

\section{INTRODUÇÃO}

O Ministério da Saúde no ano de 2000 implantou a Política Nacional de Humanização da Assistência Hospitalar (PNHAS) propondo um conjunto de ações integradas que visam mudar o padrão de assistência ao usuário nos hospitais públicos do Brasil, melhorando a qualidade e a eficácia dos serviços prestados por estas instituições. Posteriormente, a fim de efetivar os princípios do SUS criou-se em 2003 a Política Nacional de Humanização (PNH), considerando a humanização como eixo norteador das práticas de atuação e gestão em todas as esferas do SUS. Como política, a humanização deve traduzir princípios e modos de operar no conjunto das relações entre profissionais e usuários, entre as diversas unidades e serviços de saúde, aumentando o grau de corresponsabilidade dos diferentes atores que constituem a rede SUS no cuidado à saúde. Implica em mudança na cultura de atenção aos usuários, caracterizando uma construção coletiva. 
Nessa medida, segue os seguintes princípios: valorização da dimensão subjetiva e social em todas as práticas de atenção e gestão, fortalecendo e estimulando processos integradores e promotores de compromissos/responsabilização; estímulo a processos comprometidos com a produção de saúde e com produção de sujeitos; fortalecimento de trabalho em equipe multiprofissional, estimulando a transdisciplinaridade e a grupalidade; atuação em rede com alta conectividade, de modo cooperativo e solidário em conformidade com as diretrizes do SUS; utilização da informação, da comunicação, da educação permanente e dos espaços da gestão na construção de autonomia e protagonismo de sujeitos e coletivos (BRASIL, 2004).

A humanização tem sido associada a diferentes e complexas categorias relacionadas à produção e gestão de cuidados em saúde, tais como: integralidade, satisfação do usuário, necessidades de saúde, qualidade da assistência, gestão participativa, o protagonismo dos sujeitos, além de uma assistência capaz de prover acolhimento e resolutividade. A humanização vem sendo algo essencial nas ações dos profissionais de saúde, nos programas e projetos que envolvem ações de educação, promoção e prevenção em saúde, sendo necessário realçar a necessidade da dimensão humana no cuidado da dor e do sofrimento, principalmente no âmbito hospitalar.

Nesse sentido Leo Pessini (2004) afirma que:

Numa primeira aproximação à questão da humanização da dor e do sofrimento humano no contexto hospitalar, constatamos que passamos por uma profunda crise de humanismo. Falamos insistentemente de ambientes desumanizados, tecnicamente perfeitos, mas sem alma e ternura humanas. A pessoa humana vulnerabilizada pela doença deixou de ser o centro das atenções e passou a ser industrializada em função de um determinado fim, que pode variar: transformá-la em objeto de aprendizado, usá-la 
em benefício do status do pesquisador, tratá-la como cobaia de pesquisa (2004, p. 12).

Como humanos podemos constituir ações "humanizantes" que considera o outro em seus direitos, em sua singularidade e integralidade; enfim, em sua dignidade e, ao mesmo tempo, somos capazes também de constituir ações "desumanizantes" que "coisificam" o outro ou nós mesmos, indicando a ação de não reconhecer o doente como pessoa e sujeito, mas como objeto da intervenção clínica, com necessidades padronizadas, destituídas de poder e de sentimentos. Percebe-se ainda a desumanização pela tecnologia, na qual o cuidado é realizado por intermédio de máquinas e procedimentos, tornando a interação entre o doente e o cuidador um momento eventual, suplementar, dispensável ou mesmo ausente.

Outra forma de desumanização está ligada especificamente à relação com o doente, como o anonimato, a despersonalização, a falta de privacidade, a aglomeração, a falta de preparo psicológico e de informação, bem como, a falta de ética e a quebra do sigilo por parte de alguns profissionais: o doente é um número, um caso, uma patologia, objeto de atividades, mas não um centro de interesse, um sujeito em sua totalidade.

Vale ressaltar que esta “desumanização” é também uma das consequências do capitalismo, este que visa apenas o lucro, o individualismo e o consumismo, deixando de lado o ser humano com os seus valores. Desta forma, o ser humano passa a pensar em seus valores quando já não tem mais utilidade para o capital, ou seja, a partir do momento que o indivíduo é excluído da sociedade do trabalho e consequentemente do consumo, tornando-se público-alvo da solidariedade ou por assim dizer, das ações humanizadas.

No que diz respeito à realidade da saúde no Brasil encontra-se situações que descrevem um cenário que revela o descaso com o ser humano como a espera em Revista Serviço Social \& Saúde. UNICAMP Campinas, v. X, n. 12, Dez 2011 
grandes filas e demora no atendimento; ausência ou número reduzido de profissionais especializados atuando, uma vez que as contratações ainda estão voltadas, com ênfase aos médicos, enfermeiros e técnicos de enfermagem, a complementação dos serviços de saúde com o setor privado, dentre outras. Outro fato a ser considerado é o de que as pessoas só procuram assistência à saúde quando o seu quadro de doença já está avançado, reinserindo constantemente no setor terciário de saúde.

Quanto aos profissionais atuantes na área da saúde, espera-se que estes ampliem o diálogo entre várias profissões que compõem a atuação na área, entre os profissionais e a população e entre os profissionais e a administração, promovendo assim, a gestão participativa e o conceito de clínica ampliada, cuja definição pode ser entendida como o compromisso com o sujeito e seu coletivo, estímulo a diferentes práticas terapêuticas e co-responsabilidade de gestores, trabalhadores e usuários no processo de produção de saúde. Espera-se ainda a sensibilização das equipes de saúde em relação ao problema da violência intrafamiliar (criança, mulher e idoso) e quanto à questão dos preconceitos (sexual, racial, religioso, entre outros) no momento da recepção e dos encaminhamentos.

Um dos objetivos da proposta de humanização engloba a criação de uma diferente ou uma nova cultura do atendimento, fundamentada na base do diálogo e do cuidado. O espaço das relações entre profissionais e usuários e o espaço entre os diversos serviços diferenciados em nível tecnológico e de especialidades seriam o lócus privilegiado dessa nova cultura. A humanização pode ser vista como uma política transversal a permear todos os programas e formas de atendimento do sistema.

Nesta direção, Ayres (2008, p. 57) afirma que:

Há que se buscar, portanto, junto das finalidades técnicas das práticas de saúde, mas transcendendo sua condição de estrita produção de objetos (os produtos do trabalho da saúde), a Revista Serviço Social \& Saúde. UNICAMP Campinas, v. X, n. 12, Dez. 2011 
antecipação, escolha e negociação de uma vida boa, ou seja, do melhor possível a fazer diante do projeto de felicidade que se coloca em questão naquele momento.

Desta forma, a Residência Integrada Multiprofissional em Saúde apresenta-se como um espaço privilegiado de atuação, no qual é possível estabelecer diálogo com os diversos profissionais, usuários, familiares e instituição, no qual o assistente social pautado no Código de Ética e no projeto ético político profissional desempenha um importante papel na implementação de um novo modelo de assistência.

\section{A trajetória histórica da assistência em saúde e a humanização: algumas considerações}

Na atualidade, uma das preocupações centrais das políticas de saúde no Brasil tem se constituído na abordagem (e execução) de programas que visem o trabalho da humanização dos serviços de saúde. Pode dizer então que humanizar os serviços ou atendimentos da saúde significa compreender de maneira ampliada as várias dimensões do humano, na assistência em saúde. Humanizar de forma comum pode trazer a luz uma grande indagação: como humanizar (ou re humanizar) um serviço ou atendimento da saúde quando todos os envolvidos no processo se constituem em "pessoas humanas”?

Contudo, para fazer uma aproximação dessa “resposta” é necessário retomar aspectos históricos da saúde, bem como aos sujeitos atuantes nesse cenário. A saúde, nos seus primórdios, tem na imagem do contato direto uma de suas principais tônicas: antes, o cuidador e o ser cuidado se faziam próximos, numa relação de reciprocidade, e, não raro, de intimidade; o médico se apresenta como principal cuidador, amplamente valorizado pelas famílias e, como elemento a contribuir para o aconselhamento desta e, nessa medida, a incutir valores e padrões de comportamento. 
Séculos adentro, ao ingressar no universo das revoluções tecnológicas, a Medicina converte a fragmentação do corpo em especialidades, exprimindo as diretrizes cartesianas e, dessa forma o ser cuidado passa a ser entendido como um ser “multifacetado"; o processo de unificação desse ser ficaria remetido a sua dimensão espiritual. Com o advento das revoluções industriais, a Medicina passa a ser processada como veículo das tecnologias, imprimindo assim uma marca tecnotrônica, ou seja, os exames dão lugar à experiência clínica e, não raro o atendimento em saúde se dá pela via da interpretação dos resultados magnetizados das radiografias entre outros. Assim, verifica-se o distanciamento do cuidador do ser cuidado, estando este, numa dinâmica interminável de exames e radiotecnologias (REZENDE, 2010).

Na contemporaneidade, a impressão que se torna evidente é a retomada da assistência em saúde tendo como premissa o contato, a escuta do paciente, sujeito imprescindível no processo de tratamento e/ou cura. Mais que elementos essenciais objetivos, a subjetividade se coloca como elemento possível ao entendimento e encaminhamento da atenção à saúde.

Desde a antiguidade, a palavra era o instrumento utilizado para a transmissão de conhecimentos, e a educação se constituía na mais elementar, contudo necessária, via de demover o homem de seu status de doença, podendo assim, adentrar o universo da saúde, obviamente que não com o sentido que apreendemos hoje, mas de saída do espaço doente. Recorrendo ao médico Hipócrates (nascido em Cós, aproximadamente no ano 460 a.C), pai da Medicina antiga (e moderna), tem-se: “Quando as palavras não curam, as ervas curam. Quando as ervas não curam, o bisturi cura; quando o bisturi não cura, a morte cura...”. Assim, as doenças não são consideradas isoladamente e como um problema especial, mas é no homem, vítima da enfermidade, com toda a natureza que o 
rodeia, com todas as leis universais que o rege e com a qualidade individual dele, que o médico fixa com segura visão ${ }^{10}$.

Originalmente, a Medicina ocidental trata o homem como um ser dotado de corpo e espírito, cuja tônica principal é reconhecê-lo como parte integrante da natureza. O homem não só faz parte da natureza, mas se adentra a ela e não o contrário.

A Medicina não destitui ou abandona a visão humanística; não se tratava somente do cuidar técnico, mas, configura-se um profundo conhecedor da alma humana, na vida e sobre a morte. Esta passa assim, a assumir outros papéis dentro do espaço social, nas artes, nas ciências, na política, na literatura e outras áreas da predileção e trânsito social, corroborando para a construção e disseminação de saberes através de vários veículos de comunicação.

Nesse mesmo século, com as importantes descobertas principalmente no campo da microbiologia, revela-se o milagre da transformação do microorganismo em medicamento, e outros elementos que oferecem um efetivo salto em direção à cura das enfermidades, depositando nessa técnica, grande desejo de vida melhor e, remete a Medicina a apoiar-se de forma profunda nas ciências exatas e nas ciências biológicas. A filosofia e a história passam a ser atributos secundários do entendimento do ser humano, do ser doente. Como resposta a esse processo inclusive, outras categorias profissionais, como o Serviço Social e a Psicologia, são convidadas a atuar na assistência em saúde; especificamente no caso do Serviço Social, no Brasil, para compor as equipes de atenção nos vários segmentos, tanto nos espaços dos hospitais, como na atenção básica.

Atualmente, a especialização do saber é a tônica. O profissional da saúde torna-se um especialista de partes que compõe um todo, pois esta totalidade envolve vários atores como: os profissionais da saúde de várias áreas de formação e o paciente a

\footnotetext{
${ }^{10}$ Disponivel em http://www.hottopos.com/convenit2/rehuman.htm. Acesso em março, 2010. Revista Serviço Social \& Saúde. UNICAMP Campinas, v. X, n. 12, Dez 2011
} 
partir de sua realidade social. Submerso nessa complexidade do saber multifacetado, vêse surgir um possível efeito colateral: a desumanização da assistência em saúde. Tal questão é ratificada por Caprara e Franco (2008, p. 91) quando afirmam que:

Entre médico e paciente, mesmo que não intencionalmente, existe o exercício da interpretação: do sofrimento em queixa, da queixa em sintomas, dos sintomas inseridos em uma história. As condições de vida, a epidemiologia, os exames laboratoriais, o raciocínio clínico, a suspeita, o diagnóstico completam o ciclo. Nesta perspectiva, até que se 'feche um diagnóstico' muitos círculos hermenêuticos terão sido construídos.

Contraditoriamente, fruto de sistemas convidativos a poliespecializações, o trabalhador da saúde, grande empreendedor do processo de cura, depara-se com intensos conflitos ocasionados, em grande parte, pela precarização das relações de trabalho, cujos reflexos são constatados pelas estratégias utilizadas quando no desempenho de suas funções, tanto no setor público, quando no setor privado.

Vítimas das várias jornadas de trabalho e da grande demanda de atendimentos, somadas ao descompasso ou precariedade da formação profissional ofertada pelas Instituições formadoras, o profissional se defronta com fortes conflitos nas relações de vínculos com o "paciente", comprometendo sobremaneira o processo de cura e prevenção e, em consequência, a humanização das relações estabelecidas nesse universo.

A possibilidade de alteração desse status de desumanização por meio da interdisciplinaridade se faz presente no cotidiano dos trabalhadores de saúde. Farinelli (2008, p. 43) salienta em seus estudos que "pensar no trabalho realizado por uma equipe interdisciplinar pressupõe o conhecimento da totalidade do ser humano, enquanto celeiro de vivências fisiológicas, sociais, emocionais, culturais e políticas”. E acrescenta 
“o saber parcelado não é capaz de produzir o entendimento estruturado, mas o valor da interdisciplinaridade é capaz de realçar os vários saberes e colocá-los a serviço dos sujeitos com os quais trabalhamos”.

O desafio do trabalho interdisciplinar é saber distinguir, não fazer da parcela o seu fundamento. Não é possível fragmentar a realidade em modelos fechados. O trabalho interdisciplinar construído gradativamente pela equipe de profissionais somados aos pressupostos básicos do SUS - Sistema Único de Saúde, de universalidade, de equidade e de justiça social são condições para que entenda e atenda o “paciente” enquanto sujeito no processo de sua melhora.

\section{SERVIÇO SOCIAL E HUMANIZAÇÃO NA SAÚDE}

Discutir o trabalho do assistente social na área da saúde com enfoque na Política de Humanização nos remete a algumas características que desvendam a particularidade desse complexo processo de trabalho, no qual os profissionais são historicamente e culturalmente identificados como um dos profissionais da saúde que também se dedica às questões relativas à humanização do atendimento. Alves, Mioto e Gerber (2007, p. 47) ressaltam que “a preocupação dos assistentes sociais coma resolutividade do sistema de saúde, de apurar no dia-a-dia seus princípios e diretrizes, deve vir acompanhada por uma visão analítica sobre o processo saúde-doença e de adensamentos conceituais que dão conta de responder ao modelo de atenção vigente”.

Neste sentido, faz-se necessária uma reflexão crítica, sobretudo se considerarmos que tal reconhecimento do profissional de Serviço Social em lidar com a questão da humanização. Castro (2000) aponta a história do Serviço Social associada à tradição e à influência do pensamento humanista cristão, uma vez que na gênese do 
Serviço Social no Brasil, o homem era visto como indivíduo isolado, necessitado de ajuda de pessoas e profissionais de boa vontade.

Esta concepção de homem e a perspectiva de intervenções isoladas e pontuais identificadas no contexto histórico do Serviço Social vão ao encontro da concepção de saúde restrita à assistência médica individual que elege como objeto de suas ações o alívio de tensões derivadas de "situações” problemas, ou seja, a harmonização das relações.

A partir das décadas de 1950 até início da década de 1980, com o Movimento de Reconceituação, ocorre uma profunda revisão crítica do Serviço Social tradicional tanto nos fundamentos teórico-metodológicos e éticos políticos quanto ao perfil profissional, conferindo a possibilidade de construção de novas formas de sociabilidade com o protagonismo dos sujeitos coletivos.

Segundo Guerra (2002), o projeto de formação profissional pretende ser a mediação capaz de objetivar aquele perfil de profissional forjado no projeto éticopolítico profissional, capaz de compreender o significado político da sua profissão e que saiba analisar teoricamente os processos sociais sobre os quais a sua ação se debruça.

A partir do Movimento da Reforma Sanitária, nos anos 1980, inicia-se um novo projeto de saúde no qual é concebida como direito de todo cidadão a ser garantido pelo Estado, tendo como princípios a equidade do atendimento, a integralidade da atenção e a participação social do usuário. A partir dos anos 1990, com a implementação do Sistema Único de Saúde (SUS), mudanças de ordens tecnológica, organizacional e política passaram a exigir novas formas de organização do trabalho na saúde, determinadas pela hierarquização por nível de complexidade, descentralização e democratização do sistema, imprimindo novas características ao modelo de gestão e atenção e, portanto, aos processos de trabalho. Se houver uma compreensão acerca dos 
processos históricos que contribuíram e que legitimaram a constituição deste direito, a abordagem profissional será diferenciada ao colocar como direito social o que muitas vezes é apreendido como “benesse” do mercado.

Apesar de todas as mudanças positivas que ocorreram na atual organização do Sistema de Saúde, ainda não foram superadas algumas contradições como a demanda reprimida, a precariedade dos recursos, a questão da quantidade e da qualidade da atenção, a burocratização e a ênfase na assistência médica curativa individual. Faz-se necessário centrar suas ações nas reais necessidades de saúde da população e articular ações intersetoriais com as demais políticas sociais que intervêm nas condições de vida da população, como é o caso da habitação, do saneamento, das condições de trabalho, da educação, da assistência, da previdência, do acesso a terra, entre outras.

Ao reconhecer a saúde como resultante das condições de vida, a obtenção de dados sobre as condições econômicas, políticas, sociais e culturais passa a fazer parte do conjunto dos procedimentos necessários à identificação e análise dos fatores que intervêm no processo saúde/doença, colocando a saúde como problemática coletiva, superando seu enfoque curativo e individual. É nesse contexto que emergem um conjunto de requisições expressivas da tensão existente entre as ações tradicionais da saúde e as novas proposições do SUS e que também determinam o âmbito de atuação do profissional de Serviço Social.

Conforme Pontes (2000), o Serviço Social caracteriza-se por ser uma profissão interventiva, por isso necessita, além de conhecer a realidade na sua complexidade, criar meios para transformá-la na direção de determinado projeto socioprofissional. Nesse sentido, sob a ótica do autor:

Quando um problema de um pequeno agrupamento de pessoas (ou até de um único indivíduo) que vive num mundo isolado, 
portanto, abstrato, passa a ser compreendido como pertencente a tantos outros indivíduos, grupos, povos, etc. (segmentos sociais), então, aquela situação única, que se afigurava no plano da singularidade como problema individual-familiar, mediatizase. Essa mediação se dá pelas leis sociais e particulariza pelas determinações históricas, ganhando, por aproximações sucessivas, concretude no entrecruzamento dos complexos sociais que compõem a realidade (PONTES, 2000, p. 47).

Neste contexto, o assistente social é um profissional capacitado para articular, identificar e produzir informações acerca da realidade social marcada pelas contradições que se traduzem na desigualdade que a desumaniza.

O Serviço Social, como uma das formas institucionalizadas de atuação nas relações entre os homens no cotidiano da vida social tem como recurso básico de trabalho a linguagem. O assistente social é chamado a se constituir como uns dos agentes intelectuais de "linha de frente” nas relações entre instituição e população, entre os serviços prestados e a solicitação desses mesmos serviços pelos interessados. A prática profissional do conjunto da categoria dispõe de condições potencialmente privilegiadas para apreender as particularidades que emergem no cotidiano das classes populares, por estar presente nas mais variadas expressões de suas esferas da vida (IAMAMOTO, 1992).

O cotidiano do trabalho do assistente social apresenta-se como um campo de expressões concretas das desigualdades, onde os direitos sociais são constantemente ameaçados, inclusive no que se refere ao direito à vida. A veiculação de informações passa a ser um elemento determinante numa prática que priorize as demandas da população usuária. O assistente social tem o compromisso ético-político de trazer para o 
espaço institucional a informação, o conhecimento e o saber desconhecido pela população usuária.

\section{Experiência do Serviço Social enquanto prática humanizada no Programa de Residência Integrada Multiprofissional em Saúde: o caso da RIMS/ UFTM}

O Programa de Residência Integrada Multiprofissional em Saúde se constitui numa forma de educação continuada na área de formação dos recursos humanos em saúde na qual se privilegia a complementaridade entre conhecimentos, destacando as relações mútuas entre as profissões, o potencial em realizar trabalhos conjuntos, incorporando as bases de trabalho coletivo na área da saúde. Neste âmbito, a lei $\mathrm{n}^{\circ}$ 11129 de 30 de junho de 2005 institui a Residência em Área Profissional da Saúde, definida como modalidade de ensino de pós-graduação lato sensu o qual se orienta pelos princípios do Sistema Único de Saúde - SUS. Tem a formação multiprofissional com perspectiva interdisciplinar, integrando conceitos e construindo em conjunto objetos de novas investigações, absorvendo os condicionantes deste processo e sinalizando para a busca de alternativas e de resolutividade de acordo com a política de saúde.

A Residência Integrada Multiprofissional em Saúde da Universidade Federal do Triangulo Mineiro - UFTM teve inicio em março de 2010, estruturada em três áreas de concentração, sendo, saúde da criança e do adolescente, saúde do adulto e saúde do idoso, integrando as seguintes profissões: Enfermagem, Fisioterapia, Nutrição, Psicologia, Serviço Social e Terapia Ocupacional.

O Serviço Social sendo uma profissão que assumiu compromisso éticopolítico “com a democracia, a liberdade e a justiça social” (CFESS, 1993), tem por objeto de trabalho as expressões da questão social e uma formação teórico- 
metodológica e ético-política que o habilita a lidar com a realidade da classe trabalhadora em seu cotidiano, desempenhando um importante papel na consolidação do direito à saúde e consequentemente no atendimento humanizado.

Nesta direção pode-se ressaltar também o fato de que o Serviço Social foi reconhecido como uma das quatorze profissões da saúde por meio da Resolução CNS $n^{\circ}$ 218, de 06 de março de 1997. Esta mesma Resolução ratifica o que foi discutido na $8^{\text {a }}$ Conferência Nacional de Saúde, que

[...] concebeu a saúde como 'direito de todos e dever do Estado' e ampliou a compreensão da relação saúde/doença como decorrência das condições de vida e trabalho, bem como do acesso igualitário de todos aos serviços de promoção, proteção e recuperação da saúde, colocando como uma das questões fundamentais a integralidade da atenção à saúde e a participação (Resolução CNS nº 218, 1997, p. 1).

Neste sentido, a inserção do Serviço Social no Programa de Residência Multiprofissional em Saúde (RIMS) reflete o reconhecimento social da profissão pela concepção ampliada de saúde e caracteriza se como novo espaço de formação. Assim, a perspectiva do Serviço Social na RIMS-UFTM, enquanto uma profissão que atua diretamente na realidade social, é de mostrar que os aspectos sociais, econômicos, políticos e culturais interferem diretamente nas condições de saúde dos usuários e que devem ser considerados nas ações e serviços de saúde.

A Lei de Regulamentação da Profissão n 8662/1993, artigos $4^{\circ}$ e $5^{\circ}$ que trata das competências e atribuições privativas do assistente social ratificam a capacidade do profissional realizar leitura crítica da realidade social, inclusive dos usuários dos serviços de saúde, e propor estratégias para o enfrentamento das demandas apresentadas no cotidiano profissional, tendo como respaldo o projeto ético-político da profissão, que 
tem o compromisso com os usuários, visando à efetivação dos direitos sociais, numa perspectiva de emancipação social dos sujeitos.

A partir da aproximação à realidade socioeconômica, política e cultural dos sujeitos atendidos pelos serviços de saúde, o assistente social pode apontar perspectivas de intervenções que possam contribuir com os demais trabalhadores da saúde, de forma a ver o usuário dos serviços de saúde na sua totalidade. Diante da complexidade da realidade, o assistente social busca conhecer as condições para contribuir para o acesso aos recursos e às informações sociais, políticas e culturais de maneira diferenciada, promovendo a perspectiva dos direitos políticos, civis e sociais. Assim, para edificar esse processo tem-se que:

O trabalho de educação e informação em saúde constitui um dos objetivos da residência em Serviço Social, dada a sua importância na prevenção e promoção da saúde, na divulgação e criação de uma cultura de direitos junto aos usuários do SUS e na reflexão sobre o conceito ampliado de saúde a partir de suas condições de vida. Este processo denominado abordagem social privilegia dados relativos às condições sanitárias, habitacionais, imposição familiar, emprego, renda e responde pela necessidade de sistematizar informações sobre as condições de vida do usuário e sua família. Sua finalidade é conhecer as variáveis que interferem no processo saúde/doença, no diagnóstico e tratamento a fim de agilizar o fluxo de informações e comunicação entre o serviço e família do usuário para impulsionar a resolução de problemas emergentes no decorrer do processo de prestação de serviços (MOTA, 2006, p. 364).

Pensar o projeto profissional supõe traduzir os limites e as possibilidades com competência para propor, para negociar com as instituições os seus projetos, para defender o seu campo de trabalho, suas qualificações e atribuições profissionais. Dessa 
forma, a atuação dos profissionais do Serviço Social na RIMS será pautada nos onze princípios do Código de Ética profissional dos assistentes sociais (1993), especialmente na defesa dos direitos humanos e sociais; na ampliação e consolidação da cidadania e democracia; no posicionamento a favor da equidade e justiça social; na qualidade dos serviços prestados e no exercício profissional sem ser discriminado ou discriminar.

O Serviço Social na residência multiprofissional, por meio do trabalho humanizado com os diversos segmentos - como crianças e adolescentes, adultos e idosos - está construindo sua identidade de forma a valorizar a importância do sujeito social no cotidiano da prática social.

É no espaço de escuta e do diálogo entre assistente social e usuários e entre assistente social e equipe de saúde que se constroem processos de fortalecimento de uma política de humanização, pois se atua diretamente com o interesse coletivo e com a vida cotidiana dos sujeitos. Para embasar essas ações tem-se um projeto profissional interligado a um projeto societário que visa com prioridade o acesso à cidadania e o respeito aos diversos aspectos culturais, econômicos e políticos. A partir desta atitude pode-se afirmar que o profissional que é capaz de humanizar a prática, consolida sua identidade profissional fortalecendo-se enquanto ser humano.

O contato com a realidade hospitalar e ambulatorial realizado por meio de observações, acolhimento, acompanhamento de visitas médicas ao leito, acompanhamento de consultas médicas, discussões de casos, possibilita ao profissional e equipe identificar variadas demandas apresentadas pelos usuários.

No cotidiano profissional, os usuários em sua maioria desconhecem seus direitos e responsabilidades enquanto cidadão tais como: questões trabalhistas, acidentes pessoais, seus direitos de usuários dos serviços de saúde, ausência de informações e conhecimentos relacionados à promoção da saúde, à prevenção de 
doenças, danos e riscos e à recuperação em saúde; acesso inviabilizado aos serviços de saúde; entre outros.

A atuação profissional no contexto hospitalar coloca o assistente social frente a uma realidade que requer sucessivas reflexões acerca do processo de humanização das ações no trato com a vida, em todas as suas expressões, incluindo a finitude. Permite espaços de escuta e acolhimento no momento de desconforto emocional que acompanha o adoecimento. O alcance do olhar do assistente social deve transcender a situação posta para buscar núcleos de apoio na família, na comunidade, na rede de apoio social, buscando assim, formas de enfrentamento e/ou superação.

A humanização visa a valorizar as relações no ambiente hospitalar, resgatar o respeito e a dignidade, bem como atender o usuário em todas as dimensões. Embora pareçam questões básicas na atenção na saúde (e que assim deve ser encarado), muitas ações requerem empenho para que tal processo se edifique a luz do direito do usuário do serviço de saúde.

Para Ayres, (2008, p. 70)

Não parece difícil aceitar que talvez a mais básica condição de possibilidade da inflexão de ações de saúde na direção do cuidar é o privilegiamento da 'dimensão dialógica' do encontro entre usuários e profissionais. Isto é, a abertura a um autêntico interesse em ouvir o outro, rompendo o monólogo próprio à discursividade tecnocientífica. Poder ouvir e fazer-se ouvir, polos indissociáveis de qualquer legítimo diálogo, é o elemento que faz efetivamente surgir na cena do cuidado não um sujeito (profissional da saúde) e seu objeto (usuário ou comunidade), mas dois sujeitos e um objeto mediador (riscos, dismorfias, disfunções, sofrimentos, etc.). 
Nesta perspectiva, os profissionais que compõe a Residência Integrada Multiprofissional em Saúde (RIMS), a fim de contribuir com um modelo de reorientação das práticas em saúde no ambiente hospitalar pautados na lógica da humanização em saúde desenvolveram os seguintes projetos:

\section{- Projeto Integrando Equipes}

Grupo composto pelos profissionais da área de concentração em saúde do idoso junto aos profissionais de enfermagem, auxiliares e técnicos que atuam na Clínica Médica do Hospital de Clínicas da Universidade Federal do Triângulo Mineiro - HCUFTM - com o objetivo de promover o estabelecimento de vínculos, a integração entre os membros das equipes e a sensibilização para um processo de humanização interna que tenha consequências no atendimento prestado aos usuários. Realiza discussão de temas relacionados à humanização, saúde do trabalhador, troca de experiências sobre a rotina e organização do trabalho, bem como aspectos técnicos referentes ao trabalho em enfermagem.

A humanização deve contemplar não apenas os usuários, mas também os profissionais em saúde, os quais necessitam também de um acolhimento e um olhar para a sua saúde e bem estar de forma integral, de forma que este movimento se traduza em um melhor atendimento por parte desses profissionais em relação aos usuários.

O projeto foi implantado em 2010. No início os profissionais de saúde foram convidados e o grupo gestor percebeu grande resistência quanto a participação. O interesse era observado, porém a frequência insuficiente para os propósitos do projeto. Com o desenvolvimento dos encontros verificou-se que os profissionais reconheceram o espaço de participação como troca de experiência e reflexões do cotidiano. 
- Projeto cuidando do cuidador

Considerando a relevância da atenção à saúde da pessoa idosa, a importância do cuidador enquanto integrante do processo de assistência e a importância do autocuidado foi criado este projeto para atuar junto aos cuidadores, promovendo a prevenção e promoção da saúde. Tem como objetivo propiciar atenção e suporte aos cuidadores dos idosos hospitalizados durante o processo de assistência intra-hospitalar numa perspectiva multiprofissional e interdisciplinar, criando um espaço para o usuário explicitar seus interesses, dúvidas e necessidades, possibilitando a troca de experiências, informações e estratégias de cuidado ao idoso, esclarecimentos quanto aos direitos sociais, além de chamar a atenção para o cuidado com a própria saúde.

- Orientações aos cuidadores de lactentes: uma proposta humanizada de intervenção Multiprofissional:

Este projeto está em fase de implantação e tem por objetivo promover a orientação de pais e/ou cuidadores de bebês internados na enfermaria de Lactentes da Unidade Pediátrica do HC-UFTM. Tem como objetivo trabalhar o cuidado e os estímulos necessários para um melhor desenvolvimento infantil e, prevenir futuras desabilidades. Espera-se que o acolhimento proposto pela equipe Saúde da Criança e do Adolescente da RIMS, possibilite momentos de escuta e orientações aos cuidadores, propiciando o vínculo entre o bebê e o cuidador.

\section{- Ações humanizadas da Residência Multiprofissional na Central de Quimioterapia}

Este projeto iniciou em outubro de 2010, com atividades coletivas, realizadas tanto com os pacientes quanto com os acompanhantes e tem por objetivo proporcionar 
aos pacientes e familiares da Central de Quimioterapia do HC-UFTM um ambiente humanizado, de escuta e acolhimento, cujo foco não seja somente o tratamento e a doença, mas a diminuição do nível de estresse desencadeado pelo ambiente e procedimentos hospitalares. Busca também, possibilitar trocas de experiências entre os sujeitos envolvidos no processo, proporcionando ainda, momentos de descontração, reflexão e informação. Espera-se com o referido projeto transformar este espaço em um ambiente humanizado, melhorando a qualidade do serviço prestado, do relacionamento entre os profissionais da equipe e destes para com os pacientes e seus familiares.

\title{
CONSIDERAÇÕES FINAIS
}

\begin{abstract}
Reconhecer o "intrínseco valor da vida humana", independentemente de status ou qualquer hierarquia, traz também ao foco do debate as questões da igualdade, equidade e a discussão, emergente naquela sociedade, sobre a saúde como direito e não como privilégio dos que podem pagar. Afirmar que cada pessoa é insubstituível é reconhecer que cada um (pacientes ou colegas) possui singularidades definidoras de uma identidade única (DESLANDES, 2006, destaque da autora)
\end{abstract}

Humanizar relações significa, de início, olhar o outro numa relação de respeito. É entender que os usuários dos serviços de saúde, são, antes de tudo, seres humanos, dotados de direitos e acesso aos serviços em condições de igualdade. Nessa medida, humanizar a relação com o usuário de saúde exige que o trabalhador valorize a afetividade e a sensibilidade como elementos necessários ao cuidar. Porém, compreendemos que tal relação não supõe um ato de caridade exercido por profissionais abnegados e já portadores de qualidades humanas essenciais, mas um encontro entre sujeitos, pessoas humanas, que podem construir uma relação saudável, compartilhando saber, poder e experiência vivida. A luta pela superação do modelo médico hegemônico Revista Serviço Social \& Saúde. UNICAMP Campinas, v. X, n. 12, Dez. 2011 
é condição essencial para a reconstrução dos processos de trabalho em saúde na perspectiva da defesa da vida, em meio aos quais também se incluem os assistentes sociais.

Conforme já destacado, no processo de humanização da assistência em saúde, é preciso que os profissionais aprendam a romper com os saberes estanques e compartimentados, e se lancem numa relação de trocas contínuas, sem a ocorrência da perda da especificidade de cada saber. O interdisciplinar efetivamente poderá contribuir na possibilidade de resgate da "humana ação" na assistência em saúde e, assim, efetivar as premissas constitutivas da Carta Magna e, oportunizar a condição digna do sujeito à condição de cidadão.

A saúde é um direito de todos e dever do Estado, garantido mediante políticas sociais e econômicas que visem à redução do risco de doença e de outros agravos e ao acesso universal e igualitário às ações e serviços para sua promoção, proteção e recuperação (Constituição Federal, art. 196).

Cabe, portanto, ao assistente social, junto aos demais trabalhadores da saúde, qualificar a sua participação na implementação da Política de Humanização, reconhecendo o homem como sujeito social inserido nas relações de produção e em classes sociais, sujeito de direitos, portador da capacidade de luta contra as desigualdades sociais e de organização para transformação da sociedade. Tal atitude ratifica a proposta do Código de Ética Profissional do Assistente Social nos princípios fundamentais “expressa valores civilizatórios e emancipatórios, de igualdade, justiça social e superação da exclusão social de classes, étnica e de gênero”.

O exercício profissional do assistente social dispõe de condições potencialmente privilegiadas para apreender o cotidiano dos cidadãos, por intervir nas 
mais variadas expressões de suas esferas da vida. A realidade do trabalho do assistente social apresenta-se como um campo de manifestações concretas das desigualdades, onde os direitos sociais são constantemente violados, inclusive o direito à vida. $\mathrm{O}$ assistente social tem o compromisso ético-político de trazer para o espaço institucional o conhecimento à luz do direito, muitas vezes, desconhecido pela população usuária.

Desta forma, o grande desafio do Serviço Social é fazer uma discussão crítica acerca das práticas de humanização no sentido de romper com as práticas individualizantes, de amenização de conflitos. Cabe a categoria avançar no sentido de construir e fortalecer práticas voltadas para potencializar a capacidade de participação enquanto deliberação de sujeitos individuais e coletivos na efetiva construção de condições objetivas dignas de trabalho e atendimento no SUS, dentre as quais se incluem não só a defesa dos direitos existentes, mas a luta pela ampliação e incorporação de novos direitos. 


\begin{abstract}
Humanization has been associated with different and complex categories related to the production and management of health care such as comprehensiveness, user satisfaction, health needs, quality of care, participatory management, role of the subject, plus a service capable of providing care, resolution, and also aim at improving the quality of life of individuals. Discuss the work of social workers in health care focusing on the Humanization Policy elicits some features that reveal the particularity of this complex work process, in which the Social Work is historically and culturally identified as one of the health professions that has dedicated to issues related to the humanization of care. This article proposes a reflection on the experience of Social Health Multidisciplinary Residency in taking as its premise the commitment to the recognition of health as a result of living conditions, derived from economic, political, social and cultural population. This experiment revealed the importance of Social Work to the multidisciplinary team in order to contribute to the articulation, identification and production of information about the social reality marked by the contradictions that result in inequality that dehumanizes, and subtract also excludes. The social worker has the ethical and political commitment to bring the institutional space to information, knowledge and knowledge unknown to the user population, thus confirming for the edification of his ethical project professional politician as well as the strengthening of actions aimed at the humanization of health.
\end{abstract}

KEYWORDS: Social Work, Multidisciplinary Residency, Humanization, Public Policies

\title{
REFERÊNCIAS BIBLIOGRÁFICAS
}

ALVES, F.L.; MIOTO, R.C.T.; GERBER, L.M.L. A Política Nacional de Humanização e o Serviço Social: elementos para o debate. Serviço Social \& Saúde. Ano VI, n. 6, p. $35-52$. 
AYRES, J. R.C. M. Cuidado e humanização das práticas de saúde. In: DESLANDES, S. F. (Org.). Humanização dos cuidados em saúde: conceitos, dilemas e práticas. Rio de Janeiro: Editora FIOCRUZ, 2006. Coleção Criança, Mulher e Saúde. 406 p.

BRASIL. Constituição de 1988. Constituição da República Federativa do Brasil de 1988. 48.ed. Rio de Janeiro: Escala, 2006.

Ministério da Saúde. Resolução n ${ }^{\circ}$ de 218 de março de 1997. Dispõe sobre os profissionais de saúde de nível superior. Disponível em: http://www.crprj.org.br/legislacao/documentos/resolucaosaude1997-218.pdf. Acesso em: 13 mar. 2011.

Lei $\mathbf{n}^{\circ} 11129$ de 30 de junho de 2005. Institui o Programa Nacional de Inclusão de Jovens - ProJovem; cria o Conselho Nacional da Juventude - CNJ e a Secretaria Nacional de Juventude; altera as Leis $n^{0}{ }^{\circ}$ 10.683, de 28 de maio de 2003, e 10.429, de 24 de abril de 2002; e dá outras providências. Disponível em: <http://www.planalto.gov.br/ccivil_03/_Ato2004-2006/2005/Lei/L11129.htm> Acesso em novembro de 2011.

. Conselho Nacional de Secretários de Saúde. Legislação do SUS / Conselho Nacional de Secretários de Saúde. - Brasília: CONASS, 2003. 604 p. Disponível em: < http://www.conass.org.br/pdfs/legislacao_sus.pdf > . Acesso em: mar. 2009.

Ministério da Saúde. HumanizaSUS: Política Nacional de Humanização: a humanização como eixo norteador das práticas de atenção e gestão em todas as instâncias do SUS. Secretaria-Executiva, Núcleo Técnico da Política Nacional de Humanização. - $\quad$ Brasília: 2004. Disponível em: < http://bvsms.saude.gov.br/bvs/publicacoes/humanizasus_2004.pdf>. Acesso em: abr. 2011. 
CAPRARA, A.; FRANCO, A.L.S. Relação médico-paciente e humanização dos cuidados em saúde: limites, possibilidades, falácias. In: DESLANDES, S.F. (Org.) Humanização dos cuidados em saúde: conceitos, dilemas e práticas. Rio de Janeiro: Fiocruz, 2006. pp. 85-108.

CFESS. Código de Ética Profissional. Brasília, 1993.

Parâmetros para atuação de Assistentes Sociais na Saúde. Grupo de trabalho Serviço Social na Saúde. Brasília, 2009. 82 p.

DESLANDES, S.F. (Org.). Humanização dos cuidados em saúde: conceitos, dilemas e práticas. Rio de Janeiro: Editora FIOCRUZ, 2006. Coleção Criança, Mulher e Saúde. $416 \mathrm{p}$.

FARINELLI, M. R. A construção do espaço profissional nas organizações de calçados de Franca - SP. Franca: UNESP. 2008. 150 p.

GUERRA, Y. Novas perspectivas de atuação profissional: o perfil do profissional hoje. In: Revista Construindo o Serviço Social. Ed. 10. Instituto de estudos e pesquisas Divisão de Serviço Social da Instituição Toledo de Ensino. Bauru: São Paulo, maio 2002.

IAMAMOTO, M.V. Renovação e conservadorismo no Serviço Social. Ensaios Teóricos. Cortez: 1992. 216 p.

MARTINELLI, M.L. O exercício profissional do assistente social na saúde: algumas reflexões éticas. Revista Serviço Social \& Saúde, ano VI, n. 6 , p. 21-34.

MOTA, A.E. Serviço Social e Saúde: formação e trabalho profissional. São Paulo: Cortez, 2006. 408 p.

PESSINI, L.; BERTACHINI, L. Humanização e Cuidados Paliativos. São Paulo: Edições Loyola/Centro Universitário São Camilo, 2004. 336 p. 
PONTES, R.N. Mediação: categoria fundamental para o trabalho do assistente social. Capacitação em Serviço Social e Política Social. Mod. 04: O trabalho do assistente social e as políticas sociais, Brasília: UNB/CEAD, 2000.

REZENDE, R.M. A assistência em saúde e a trajetória histórica: algumas considerações. Anais da IV Semana de Serviço Social do Instituto Municipal de Ensino Superior de Bebedouro - IMESB. Bebedouro, 2010. 